

Jurnal Kedokteran dan Kesehatan Indonesia

Indonesian Journal of Medicine and Health

Journal homepage: https://journal.uii.ac.id/JKKI

\title{
Protecting from collateral damage
}

Aditya Hernowo*1,2,3

${ }^{1}$ Center for Health Research, Torrens University Australia

${ }^{2}$ Department of Anatomy, Faculty of Medicine, Universitas Islam Indonesia, Yogyakarta, Indonesia

${ }^{3}$ Department of Bio and Brain Engineering, Korea Advanced Institute of Science and Technology (KAIST), Korea

\section{GUEST EDITORIAL}

\begin{tabular}{l}
\hline ART IC LE I NF O \\
*Corresponding author: \\
dr.hernowo@uii.ac.id \\
\hline DOI:10.20885/JKKI.Vol12.Iss1.art1 \\
\hline Copyright @2021 Authors. \\
This is an open access article \\
distributed under the terms \\
of the Creative Commons At- \\
tribution-NonCommercial 4.0 \\
International Licence (http:// \\
creativecommons.org/licences/ \\
by-nc/4.0/).
\end{tabular}

A

little more than one year ago (March 11th 2020), the World Health Organization (WHO) declared COVID-19 as a pandemic, just one month after the disease got its name (February 11th 2020). With a wide spectrum of signs and symptoms, surely COVID-19 is not just a bad case of cold. From being asymptomatic to being lethal, there is very much to comprehend from this novel viral infection. Here we will have a quick glance on what adverse effect the disease may have on the node of our sentience, the brain, and what we can do about it.

The presence of change in mental status prompts brain imaging in COVID-19 infection. According to Egbert and colleagues, the prevailing neuroimaging features in the acute or subacute phase of the infection are diffuse leukoencephalopathy, leukoaraiosis, or rarefied white matter. ${ }^{1}$ This can be attributable to micro-haemorrhage, cerebrospinal fluid seepage from the ventricle, disruption of the blood-brain barrier, demyelination, or gliosis. Shortly later, Choi and Lee reported that the most common brain findings in the infection are infarct, haemorrhages, and inflammation or encephalopathy. ${ }^{2}$

Both reports highlight haemorrhage as probable etiology in the visible brain changes. This notion is supported by a report published at the end of 2020. It was Lee and his collaborators who showed that the visible brain lesions are more attributable to microvascular damage similar to strokes or neuroinflammatory disorders. ${ }^{3}$ There, blood clot and fibrin deposit can be found with the usual presence of microglia and T-cells, commonly seen in brain inflammation.

Hypoxia has been an easy go-to primary suspect of various signs and symptoms when dealing with primarily respiratory failure. It is not, however, true with the secondary effect to the brain from the coronavirus infection. Though it is true that hypoxia can alter mental status through global cortical effect, evidence shows that the neuroinflammatory process can be held accountable for the bleeds and their subsequent sequelae.

In light of the available data, the use of steroids can have multiple advantages. Recovery trial had shown that short term steroids ( 10 days) reduce the mortality rate in patients requiring supplemental oxygen. ${ }^{4}$ While the steroid reduces the inflammatory response in the lungs, it might also benefit the brain, preventing neuronal inflammation. We must realize though, that steroids like dexamethasone and methylprednisolone are prothrombotic. It is not an easy task to weigh the risk and benefit of administering steroids to the patients, especially pertaining to brain protection efforts. We need to always keep in mind, COVID-19's primary victims are the lungs, but there are collaterals to be protected as well.

\section{REFERENCES}

1. Egbert AR, Cankurtaran S, Karpiak S. Brain abnormalities in COVID-19 acute/subacute phase: 
A rapid systematic review. Brain Behavior and Immunity. 2020;89:543-554.

2. Choi Y, Lee MK. Neuroimaging findings of brain MRI and CT in patients with COVID-19: A systematic review and meta-analysis. European Journal of Radiology. 2020;133:109393.

3. Lee MH, Perl DP, Nair G, Li W, Maric D, Murray H, Dodd SJ, Koretsky AP, Watts JA, Cheung V, Masliah E, Horkayne-Szakaly I, Jones R, Stram MN, Moncur J, Hefti M, Folkerth RD, Nath A. Microvascular Injury in the brains of patients with COVID-19. New England Journal of Medicine. 2021;384(5).

4. Matthay MA, Thompson BT. Dexamethasone in hospitalised patients with COVID-19: addressing uncertainties. Lancet Respiratory Medicine. 2020;8(12):1170-1172. 